\title{
Associations between biopsychosocial factors and chronic upper limb pain among slaughterhouse workers: cross sectional study
}

Emil Sundstrup ${ }^{1,2^{*}}$, Markus D. Jakobsen ${ }^{1,2}$, Mikkel Brandt ${ }^{1,3}$, Kenneth Jay ${ }^{1,4}$, Per Aagaard ${ }^{2}$ and Lars L. Andersen ${ }^{1,3}$

\begin{abstract}
Background: Knowledge of factors associated with chronic pain is necessary for preventive strategies. The present study investigates biopsychosocial differences, with specific focus on rate of force development (RFD) and work ability, between workers with and without chronic upper limb pain.

Methods: Eighty-two male slaughterhouse workers, 49 with chronic upper limb pain and 33 pain-free controls participated in the study. Maximal muscle strength, RFD, and muscle activity was determined from fast and forceful maximal voluntary contractions for the shoulder and hand. Participants filled out a questionnaire on work ability (work ability index), work disability (Work module of DASH questionnaire), fear avoidance, and self-rated health. Additionally, pressure pain threshold (PPT) was measured in muscles of the arm, shoulder and lower leg.

Results: Muscle strength and RFD (determined within time intervals of 30, 50, 100, and 200 ms relative to onset of contraction) was $28 \%$ and 58-78\% lower, respectively, in workers with chronic pain compared with pain-free controls, and paralleled by reduced muscle activity (all $p<0.001$ ). Workers with chronic pain had lower PPT of the arm, shoulder and lower leg $(p<0.01)$, and reported impaired work ability index score and general health along with higher work disability and fear avoidance compared with controls (all $p<0.0001$ ). No differences were observed between the groups in regard to age, BMI, physical activity level, job position and duration of slaughterhouse work (all $p>0.4$ ).

Conclusions: Chronic upper limb pain was paralleled by reduced neuromuscular function of the shoulder and hand along with impaired work ability, work disability and general health. Future studies on chronic pain management at the workplace should carefully consider the biopsychosocial nature of pain when designing and implementing preventive strategies.
\end{abstract}

Keywords: Rapid force capacity, RFD, PPT, Shoulder pain, Arm pain, Hand pain, Presenteeism, WAI

\section{Background}

Pain in the upper limb is frequent among employees with repetitive and forceful job tasks $[1,2]$. Slaughtering and meat processing work involve high loading intensities and cyclic repetitive muscle actions of the upper limb and thus implies an elevated risk of work-related musculoskeletal

\footnotetext{
* Correspondence: esu@nrcwe.dk

${ }^{1}$ National Research Centre for the Working Environment, Lersø Parkalle 105, Copenhagen, Denmark

${ }^{2}$ Institute for Sports Science and Clinical Biomechanics, SDU Muscle Research Cluster (SMRC), University of Southern Denmark, Odense, Denmark Full list of author information is available at the end of the article
}

disorders $[3,4]$. In line with this, we recently found among 645 Danish slaughterhouse workers a prevalence of pain in the shoulder, elbow and hand/wrist of 60,40 and $52 \%$, respectively [1]. Additionally, $38 \%$ of the workers reported work disability due to upper limb pain emphasizing the functional consequences of arm, shoulder and hand pain on daily work performance.

Pain may originate from activation of peripheral nociceptors due to tissue damage. However, when the perception of pain for some reason persists beyond the expected time for tissue healing, chronicity has occurred [5]. The 
subjective experience of chronic pain is the result of the transduction, transmission and modulation of sensory information, signifying the involvement of central mechanisms in the perception of pain [6]. Hence, general hyperalgesia, evidenced by reduced pressure pain threshold (PPT) in a non-painful part of the body, is present in many variants of chronic pain including carpal tunnel syndrome [7], fibromyalgia [8], chronic low back pain [9], and trapezius myalgia [10]. However, evidence of a central component to work related chronic pain in the upper limb is lacking.

Chronic pain negatively impacts muscle functioning, evidenced by impaired maximal force production, motor control and endurance in painful conditions compared with healthy controls [11-13]. Additionally, previous research on office workers with trapezius myalgia showed, in a cross-sectional design, a markedly lowered rapid force capacity and neural drive during the initial phase of a maximal voluntary contraction [14]. Rate of force development (RFD) is influenced by both neural and muscular factors, encompassing central efferent neural drive, muscle fiber size and architecture along with maximal muscle strength [15-19]. Overall considered, there seem to exist a neurogenic inhibitory mechanism that limits rate of force development of chronically painful trapezius muscles. In line with this, chronic pain is a multifactorial experience composed of a multitude of complex biopsychosocial interactions, and likewise functional capacity assessments in these individuals are determined by biological, psychological and social factors [20]. Fear avoidance (i.e. the belief that movement exacerbates pain) along with musculoskeletal pain itself are examples of psychological factors that can influence patients physical performance [20-22] and could in theory inhibit efferent neural motor drive during fast and forceful movements. It is however unknown to what extent chronic upper limb pain inhibit activation and function of shoulder and hand muscles in workers with heavy and repetitive manual job-tasks, and whether pain related beliefs are impaired as a consequence of these pains.

Work related chronic pain is often accompanied by an escalating imbalance between work demands and individual resources, consequently affecting work ability [23]. In line with this, workers exposed to highly repetitive and forceful exertion, lack of sufficient recovery, and awkward postures [24, 25] have an elevated risk of both impaired work ability and musculoskeletal disorders [26-28]. Additionally, impaired work ability has been associated with loss of productivity, sickness absence, early retirement and all-cause mortality [27, 29-32]. To effectively prevent aggravation of pain and its associated harms among workers with heavy manual labor, knowledge on the biopsychosocial consequences of upper limb chronic pain are needed.
The aim of the present study was to investigate possible differences in biopsychosocial factors, with specific focus on rate of force development and work ability, between slaughterhouse workers with and without chronic upper limb pain. We hypothesized that workers with pain were expected to have impaired neuromuscular function and lower work ability score compared with pain-free controls.

\section{Methods \\ Study design}

A cross-sectional study regarding biopsychosocial consequences of chronic pain was conducted among 82 male slaughterhouse workers in Denmark, Europe. The study was a part of a randomized controlled workplace trial that was approved by The Danish National Ethics Committee on Biomedical Research (Ethical committee of Frederiksberg and Copenhagen; H-3-2010-062) and registered in ClinicalTrials.gov (NCT01716767). All experimental conditions conformed to The Declaration of Helsinki and participants were informed about the content and purpose of the study and gave their written informed consent to participate.

\section{Participants}

Eighty-two male slaughterhouse workers were recruited from two slaughterhouses in Denmark, Europe: 49 with chronic upper limb pain and 33 pain-free controls. The workers with chronic pain were recruited in relation to a randomized controlled trial concerning the effects of strength training or usual-care ergonomics on chronic pain and work disability $[2,33]$.

The two-phased recruitment process contained a brief screening questionnaire (June 2012) followed by a clinical examination and a more in-depth questionnaire (August 2012). 645 Danish slaughterhouse workers received the screening questionnaire of which 595 replied and 410 were interested to participate in the research project.

Initial inclusion criteria for participants in the chronic pain group were: 1) working at a slaughterhouse for a minimum of $30 \mathrm{~h} /$ week, 2) pain intensity in the shoulder, elbow/forearm, or hand/wrist of 3 or more on a $0-10$ VAS scale during the last 3 months, 3) stating at least "some" work disability on a five-point scale: "not at all", "a little", "some", "much" to "very much" when asked the question "During the last 3 months, did you have any difficulty performing your work due to pain in the shoulder, arm or hand?". The inspiration for this single-item question came from the work module of the DASH questionnaire [34]. Of the 410 interested respondents, 145 met the above inclusion criteria for the chronic pain group and were invited for a clinical examination. Initial inclusion criteria for participants in the pain-free control group were: 1) working at a slaughterhouse for a minimum of 
$30 \mathrm{~h} /$ week, 2) pain intensity in the shoulder, elbow/forearm, or hand/wrist of 1 or less on a 0-10 VAS scale during the last 3 months, 3) stating "not at all" work disability scoring on the five-point scale mentioned above. Of the 410 interested respondents, 50 met the above inclusion criteria for the pain-free control group and were invited for a clinical examination.

A total of 178 employees (135 with chronic pain and 43 pain-free controls) were included for the clinical examination. Furthermore, at the day of the clinical examination participants filled in another questionnaire. The following inclusion criteria applied for participants in the chronic pain group: 1) pain intensity in the shoulder, elbow/forearm, or hand/wrist regions of at least 3 on a $0-10$ VAS scale during the last week, 2) pain should have lasted more than 3 months, 3 ) frequency of pain of at least 3 days per week during the last week. The following inclusion criteria applied for participants in the pain-free control group: 1) pain intensity in the shoulder, elbow/forearm, or hand/wrist of 1 or less during the last week, 2) frequency of pain of 0 days per week during the last week.

Exclusion criteria for participants in both groups were: 1) recent traumatic injury of the neck, shoulder, arm or hand regions, 2) symptoms of carpal tunnel syndrome, 3) hypertension (Systolic BP $>160$, diastolic BP $>100$ ), 4) a medical history of cardiovascular diseases, 5) female worker. Participant flow and characteristics of participants are shown in Fig. 1 and Table 1, respectively.

\section{Outcome measures}

The following describes the experimental setup including the questionnaire and physiological test procedure. All outcome assessors were blinded to group allocation.

\section{Muscle strength and rate of force development}

Maximal voluntary contraction strength (MVC) was obtained during isometric muscle contractions performed for the shoulder- (external rotation) and wrist muscles (hand extension), using a custom-built dynamometer with 2 strain gauge load cells (KIS-2, $1 \mathrm{KN}$, Vishay Transducers Systems) [2]. During the hand extension MVC, subjects were seated upright in a chair with the elbow flexed at $90^{\circ}$ while applying outward-directed force to a vertically orientated handlebar (dynamometer setting) positioned in front of them [2]. The anterior part of the forearm was supported by the dynamometer apparatus and allowed the participants to perform maximal isometric MVC's. Maximal shoulder muscle strength (MVC) was assessed during concurrent isometric external rotation of the glenohumeral joint. During the MVCs, participants were instructed to press as fast and hard as possible [35]. Verbal encouragement and online visual feedback of the force

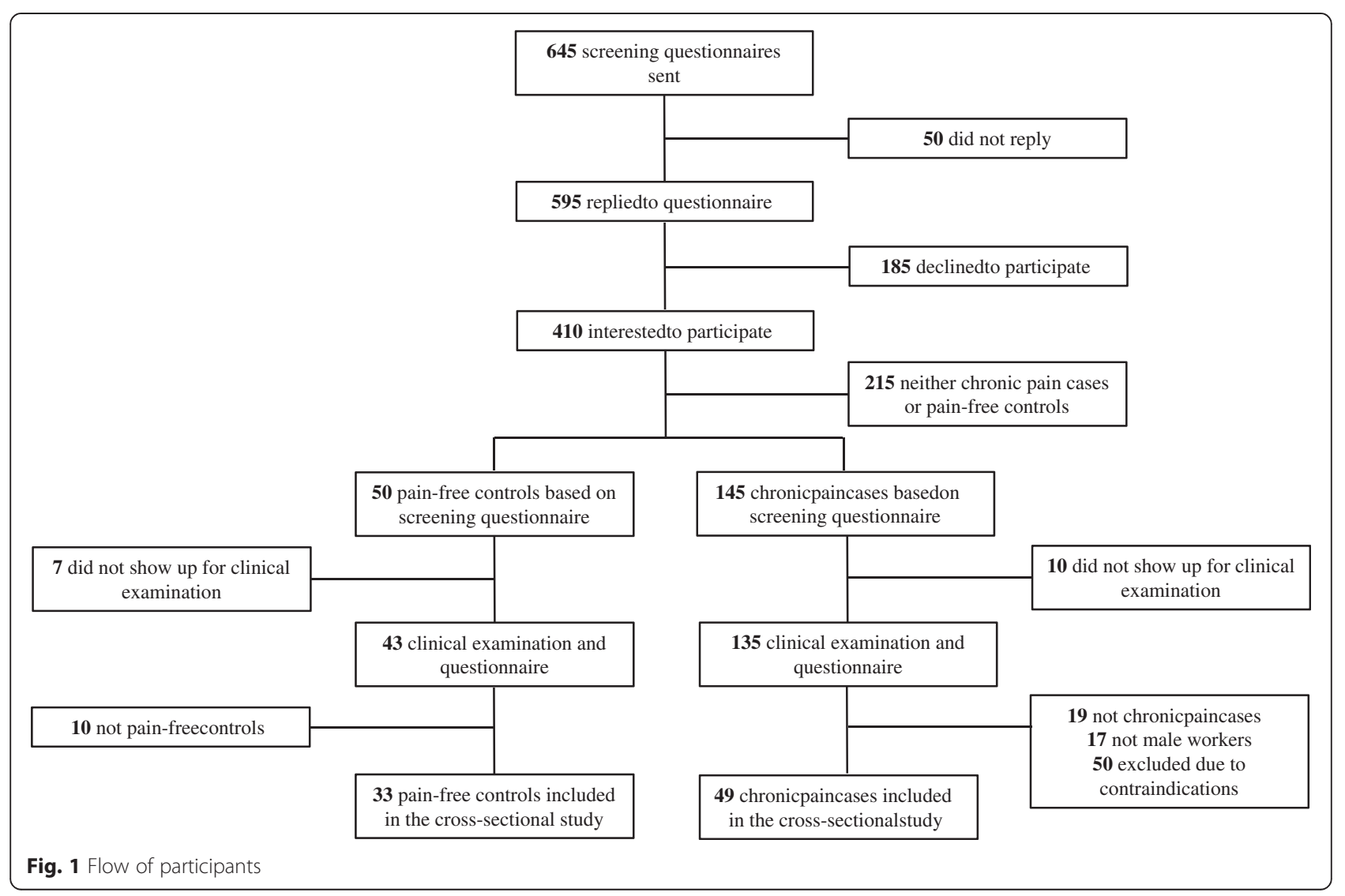


Table 1 Demographics and pain intensity of study participants. Mean (SD)

\begin{tabular}{lll}
\hline & Chronic pain & Pain-free control \\
\hline Demographics & & \\
Age (years) & $45(11)$ & $45(11)$ \\
Height (cm) & $179(7)$ & $178(7)$ \\
Weight (kg) & $90(16)$ & $87(13)$ \\
Body Mass Index (kg/m $\left.{ }^{2}\right)$ & $28(5)$ & $28(5)$ \\
$\quad$ Weekly working hours & $40(1)$ & $39(6)$ \\
$\begin{array}{l}\text { Duration of slaughterhouse work } \\
\text { (years) }\end{array}$ & $17(10)$ & $16(13)$ \\
$\quad$ Number of participants & 49 & 33 \\
Clinical & & \\
$\begin{array}{l}\text { Shoulder pain intensity previous } \\
\text { week (0-10) }\end{array}$ & $5.6(2.3)$ & $0.1(0.3)$ \\
$\begin{array}{l}\text { Elbow/Forearm pain intensity } \\
\text { previous week (0-10) }\end{array}$ & $3.9(2.7)$ & $0.0(0.2)$ \\
$\begin{array}{l}\text { Hand/Wrist pain intensity previous } \\
\text { week (0-10) }\end{array}$ & $3.7(2.9)$ & $0.2(0.6)$ \\
Pain duration > 3 months (\%) & 100 & 0 \\
\hline
\end{tabular}

exerted were given during both trials. The trial with the highest peak force was used for the subsequent analysis. Rate of force development (RFD, expressed in N/s) was determined during the early time intervals of rising muscle force $(0-30,0-50,0-100$ and $0-200 \mathrm{~ms}$ from onset of contraction) [17].

\section{EMG processing and data analysis}

Electromyography (EMG) signals were recorded from the extensor carpi radialis brevis during the hand extension MVCs and from infraspinatus during the shoulder MVCs. Electrodes were placed on the dominant side. A bipolar surface EMG configuration (Blue Sensor, Ambu A/S, Ballerup, Denmark) with an inter-electrode distance of $2 \mathrm{~cm}$ were used [36, 37]. Before affixing the electrodes, the skin of the respective area was shaved and prepared with scrubbing gel (Acqua gel, Meditec, Parma, Italy) to effectively lower the impedance. Electrode placements followed SENIAM recommendations (http://www.seniam.org). The electrodes were connected through thin shielded cables to a data-logger (Nexus10, Mind Media, Netherlands) that was placed in a flexible belt to ensure mobility during the testing procedure. EMG signals were sampled at 1,024 Hz. To ensure quality of the EMG signals, all recorded signals were visually inspected. Subsequent data filtering and data analysis was performed with custom-made Matlab programs (MathWorks).

During later off-line analysis, all raw EMG signals obtained during the MVC trial was digitally high-pass filtered using a Butterworth 4th order high-pass filter (10 Hz cutoff frequency). For each individual muscle (i.e. extensor carpi radialis brevis and infraspinatus), a moving root-mean-square (RMS; 500-ms time constant) routine was used to smooth the EMG signals and to identify peak EMG amplitude [38]. Additionally, rate of EMG rise (RER) was calculated as the slope of the filtered EMG signal during the rising phase of the EMG-time curve for all time intervals $(0-30,0-50,0-100$ and $0-$ $200 \mathrm{~ms}$ relative to onset of EMG rise).

\section{Work ability}

Work ability was rated by the work ability index questionnaire (WAI) [39]. Based on the answers of the seven items, an index score ranging from 7-49 was calculated and further classified into four categories: 7-27 (poor work ability), 28-36 (moderate work ability), 37-43 (good work ability) and 44-49 (excellent work ability) [33, 39].

\section{Pain intensity}

Pain intensity, experienced during the last 7 days, was rated subjectively using the $0-10$ modified VAS scale, where 0 indicates "no pain at all" and 10 indicate "worst pain imaginable" [40, 41]. The shoulder, elbow/forearm and hand/wrist regions were defined by drawings from the Nordic questionnaire [42].

\section{Work disability}

Participants rated work disability by the work module of the Disability of the Arm Shoulder and Hand (DASH) questionnaire: "Select which best describes your physical ability in the past week. Did you have any difficulty...1) Using your usual technique for your work? 2) Doing your usual work because of arm, shoulder or hand pain? 3) Doing your work as well as you would like? 4) Spending your usual amount of time doing your work?" Participants replied on a 5-point Likert scale from 'no difficulty' to 'unable'. For comparability with VAS pain scores, the work disability score was normalized on a scale of $0-100$, where 100 represents the highest level of disability [34].

\section{Self-rated health}

Self-rated health was evaluated with the single global health-rating item from the Medical Outcomes Survey 36 item short form (SF-36) questionnaire [43, 44]. Participants responded to the question "How do you rate your overall current health?" on a 5-point Likert scale ranging from 1 (excellent) to 5 (poor).

\section{Fear avoidance}

Fear avoidance was evaluated using a tailor-made singleitem question before and after the intervention period. Participants responded to the question: "Fast and forceful arm movement exacerbates pain in my shoulder, arm or hand?" on a 4 point Likert scale with the response options 
not at all (1), a little (2), some (3), a lot (4). This question was included because slaughterhouse work tasks commonly involve fast and forceful movement of the arm, shoulder and hands.

\section{Pressure pain threshold}

Pressure pain threshold (PPT) was assessed in the painful muscles of the shoulder and arm (infraspinatus and extensor carpi radialis brevis) and a nonpainful reference muscle (tibialis anterior) using an electronic pressure algometer (Somedic Productions AB, Sollentuna, Sweden, Europe). Pressure was manually applied perpendicular to the skin at the mid-belly of the 3 muscles at a rate of 30 kPa.s ${ }^{1}$, and the contact area of the circular probe was $1 \mathrm{~cm}^{2}$ [10]. The participant was not aware of the reading of PPT on the display, and was instructed to push the patient operated switch on a pinch handle mounted on the algometer when the sensation of "pressure" changed to "pain." PPT was measured 3 times at the infraspinatus, extensor carpi radialis brevis and tibialis anterior with $1 \frac{1}{2}$ min between each measurement alternating between the 3 muscles [10]. PPT for each muscle was subsequently expressed as the average value of the 3 measurements. Previous studies have shown satisfactory to good testretest reliability of PPT $[45,46]$.

\section{Power calculation}

The sample size calculation was based on the work ability index score (SD 4.8). If the true difference between the means in the chronic pain and pain-free control is 5 , we will need to study 34 subjects with chronic pain and 17 pain-free control subjects to be able to reject the null hypothesis that the population means of the experimental and control groups are equal with probability (power) 0.8 . The Type I error probability associated with this test of this null hypothesis is 0.01 .

\section{Statistical analysis}

Statistical analyses were performed using SAS version 9.2 (SAS Institute, Cary, NC). Because there were only two comparison groups at a single time-point, betweengroup comparisons (chronic pain vs pain-free controls) for the main variables were evaluated using unpaired $t$ testing. We used Bonferroni correction for multiple correlated end-points [47] to adjust the critical p-value, which then was set to 0.01 . Results are given as least square means and standard error (SE) unless otherwise stated. An alpha level of 0.01 or less was accepted as statistically significant.

\section{Results}

Table 1 shows demographics of the study population. No significant differences were observed for age, weight, BMI, level of physical activity, duration of slaughterhouse work, or job position (meat cutter, meat packer, slaughter) between the two groups (all $p>0.4$ ), whereas pain intensity of the shoulder, arm and hand was significant higher in the chronic pain group compared with the pain-free controls $(p<0.0001)$. Two participants in the chronic pain group did not perform the MVC tests. In the control group, the hand extension and shoulder rotation MVC's were not performed by six and eight participants, respectively. Missing EMG data from the MVC's were present in $0-6 \%$ of the participants.

There was a significant difference between groups for peak force and RFD during both shoulder rotation and hand extension (all $p<0.001$ ). Shoulder rotation and hand extension strength was $28 \%$ lower in participants with chronic pain compared to pain-free controls (Table 2; Fig. 2). RFD was 58-78 \% lower for all time intervals and contraction modes in the chronic pain group compared to pain-free individuals (Table 2; Fig. 3).

There was a significant group difference for peak EMG and RER during shoulder and hand MVC (all $p<$ 0.0001). Infraspinatus peak EMG was $34 \%$ lower, and extensor carpi radialis brevis peak EMG was $24 \%$ lower in the chronic pain group during shoulder rotation and hand extension, respectively, compared with the control group. Likewise, RER was 36-55 \% lower for all time intervals in the chronic pain group during all contraction modes (Table 2; Fig. 3).

Significant group differences were observed for work ability, DASH work module, fear avoidance and selfrated health (all $p<0.0001$ ). Work ability (WAI score) and self-rated health was lower, whereas work disability (DASH work) and fear avoidance was higher in participants with chronic pain compared to pain-free controls (Table 3, Fig. 4). All WAI single item scores, except for item 5 (sick leave during the past year; $p=0.27$ ), were significantly lower in workers with chronic pain compared to pain-free controls (all $p<0.01$; Table 3, Fig. 4). Additionally, PPT for both tibialis anterior, extensor carpi radialis brevis and infraspinatus was 21,31 and $24 \%$ lower, respectively, in workers with chronic pain compared with pain-free controls (Table 3).

\section{Discussion}

The present study showed that workers with upper limb chronic pain demonstrate depressed neuromuscular function of the shoulder and hand along with impaired work ability, work disability and general health compared with pain-free controls. Obviously differences in pain intensity and pain duration existed between workers with chronic pain and pain-free controls. However, no differences were observed between the groups in regard to age, BMI, physical activity level, job position and duration of slaughterhouse work, suggesting that other factors seem to influence why some workers experience work related chronic pain. 
Table 2 Differences in neuromuscular performance

\begin{tabular}{|c|c|c|c|c|}
\hline & Chronic pain & Pain-free Control & Between group difference & P-value \\
\hline \multicolumn{5}{|l|}{ Muscular function } \\
\hline Hand strength $(\mathrm{N})$ & 124 (112 to 136$)$ & 173 (161 to 184$)$ & $-48(-66$ to -31$)$ & $<.0001$ \\
\hline Shoulder strength (N) & 83 (75 to 90$)$ & 115 (100 to 131$)$ & $-33(-48$ to -18$)$ & 0.0003 \\
\hline \multicolumn{5}{|l|}{ Hand extension RFD } \\
\hline $0-30(N / s)$ & 128 (85 to 171$)$ & 489 (389 to 589 ) & $-361(-454$ to -269$)$ & $<.0001$ \\
\hline $0-50(\mathrm{~N} / \mathrm{s})$ & 154 (101 to 206) & 599 (485 to 713 ) & $-446(-554$ to -337$)$ & $<.0001$ \\
\hline $0-100(N / s)$ & 187 (128 to 146$)$ & 695 (581 to 808) & $-507(-621$ to -394$)$ & $<.0001$ \\
\hline $0-200(N / s)$ & 201 (151 to 252) & 576 (500 to 651$)$ & $-374(-460$ to -288$)$ & $<.0001$ \\
\hline \multicolumn{5}{|l|}{ Shoulder rotation RFD } \\
\hline $0-30(\mathrm{~N} / \mathrm{s})$ & $82(55$ to 110$)$ & 325 (193 to 458) & $-243(-343$ to -143$)$ & 0.001 \\
\hline $0-50(\mathrm{~N} / \mathrm{s})$ & 94 (62 to 125$)$ & 368 (227 to 509) & $-274(-382$ to -167$)$ & 0.0006 \\
\hline $0-100(\mathrm{~N} / \mathrm{s})$ & 119 (82 to 157$)$ & 393 (27 to 51) & $-273(-372$ to -174$)$ & 0.0001 \\
\hline $0-200(N / S)$ & 129 (95 to 163$)$ & 312 (232 to 393) & $-183(-256$ to -110$)$ & 0.0001 \\
\hline \multicolumn{5}{|l|}{ Hand extension RER } \\
\hline 0-30 (mV/s) & 155 (113 to 197$)$ & 343 (295 to 392) & $-188(-252$ to -124$)$ & $<.0001$ \\
\hline $0-50(\mathrm{mV} / \mathrm{s})$ & 141 (107 to 176$)$ & 309 (273 to 345) & $-168(-218$ to -117$)$ & $<.0001$ \\
\hline $0-100(\mathrm{mV} / \mathrm{s})$ & 132 (106 to 158$)$ & 267 (247 to 288) & $-135(-171$ to -100$)$ & $<.0001$ \\
\hline $0-200(\mathrm{mV} / \mathrm{s})$ & 117 (98 to 136$)$ & 212 (198 to 226) & $-95(-121$ to -70$)$ & $<.0001$ \\
\hline \multicolumn{5}{|l|}{ Shoulder rotation RER } \\
\hline 0-30 (mV/s) & 137 (101 to 172$)$ & 271 (223 to 320) & $-135(-193$ to -77$)$ & $<.0001$ \\
\hline $0-50(\mathrm{mV} / \mathrm{s})$ & 127 (94 to 160$)$ & 255 (215 to 296) & $-128(-180$ to -77$)$ & $<.0001$ \\
\hline $0-100(\mathrm{mV} / \mathrm{s})$ & 122 (95 to 149$)$ & 218 (195 to 243 ) & $-96(-134$ to -59$)$ & $<.0001$ \\
\hline 0-200 (mV/s) & 116 (95 to 136) & 182 (167 to 197$)$ & $-66(-93$ to -39$)$ & $<.0001$ \\
\hline
\end{tabular}

Differences in muscle strength, contractile rate of force development (RFD) and rate of EMG rise (RER) for different time-intervals during hand and shoulder MVCs in workers with chronic pain and pain-free controls. A custom made dynamometer was used to measure maximal voluntary contraction strength (MVC) during isometric contractions performed for the shoulder- (external rotation) and wrist muscles (hand extension). Results from surface EMG measurements of extensor carpi radialis brevis (during hand extension) and infraspinatus (during shoulder rotation) are also shown in the table. Mean $(95 \% \mathrm{Cl})$

Therefore it is of clinical interest to investigate the mechanisms underlying chronic upper limb pain and disability in workers with manual labor.

Maximal muscle strength and neuromuscular activity was reduced by $28 \%$ and $24-34 \%$, respectively, in the chronic pain group compared to the pain-free controls (Table 2). This illustrate that activation of chronically painful upper limb muscles is specifically inhibited during high force contractions. However, the ability to rapidly exert force (i.e. RFD) was reduced by $58-78 \%$ and paralleled by reduced muscle activity during the rising phase of muscle force (i.e. RER). Previous research on office workers with trapezius myalgia showed, in a cross-sectional design, a markedly lowered rate of force development and reduced neural drive during the initial phase of a maximal voluntary contraction compared with healthy controls [14]. The present study confirms that maximal muscle strength is less affected than rate of force development in chronically painful muscles, however this study is the first to show this in shoulder and hand muscles of workers with physical demanding manual work. The marked reduction in rate of
EMG rise observed in the chronic pain group, especially in the very initial contraction phase $(0-50 \mathrm{~ms})$, suggest that neural adaptation mechanisms may be strongly responsible for the deficit in RFD. Lowered rate of EMG rise might be explained by reduced motor neuron firing frequency and/ or recruitment of high-threshold motor units in the very initial phase of contraction $[15,48]$. However, the reduction in RFD was greater than the reduction in EMG (RER), proposing that the debilitating effect of muscle pain on rapid force capacity could also involve muscular factors such as muscular and viscoelastic atrophy. In addition, the maximal voluntary muscle contractions could in itself have aggravated pain among the workers with chronic pain, which could have lowered RFD and stopped the contraction before maximal force was reached.

General hyperalgesia, evidenced by reduced PPT in the non-painful muscle of the leg, was observed among the workers with chronic pain. This overall increase in sensitivity to pressure could reflect central sensitization, which is a phenomenon where nociceptive inputs can 


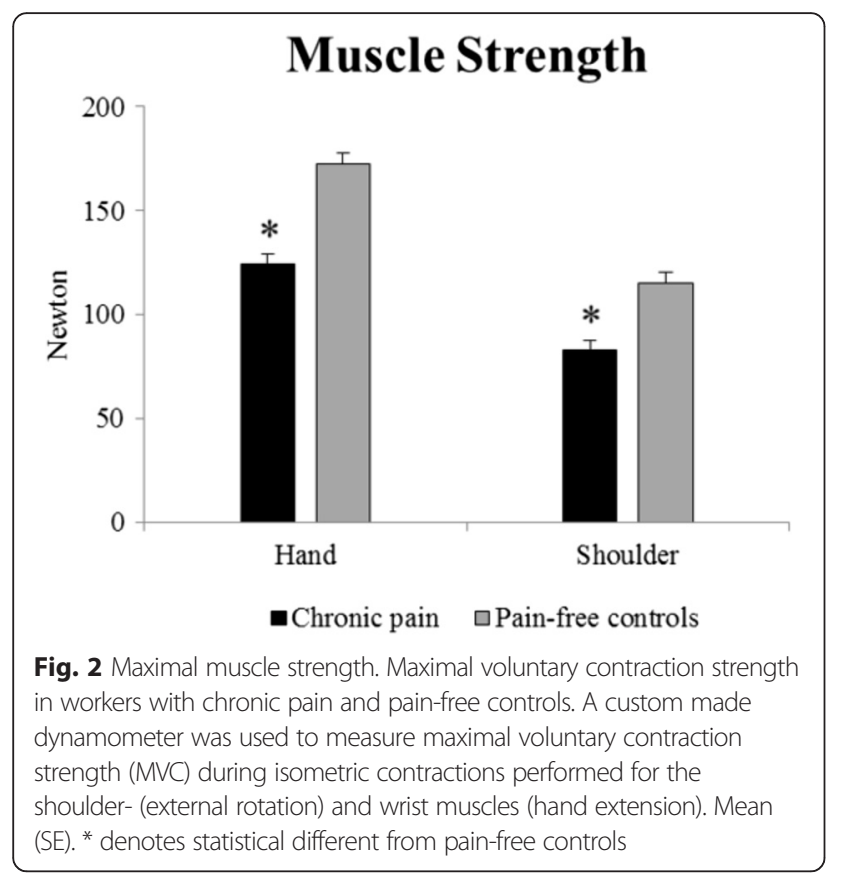

trigger excitatory synaptic responses and depressed inhibition of central nociceptive circuits, causing amplified reactions to noxious inputs [49-51]. The possible existence of central sensitization in workers with chronic upper limb pain further advocates the presence of neural alterations elicited by the persistence of pain over time, underlining the chronicity of these pains. As chronic pain is a multifactorial experience composed of complex biopsychosocial interactions, functional capacity assessments in these individuals are likewise determined by both biological, psychological and social factors [20]. Thus it could be speculated, that pain related beliefs, such as fear avoidance (i.e. the belief that fast and forceful movements exacerbated pain) might have affected the performance during the fast and forceful MVC's. Thus, pain related inhibitory feedback mediated through high force excitation of golgi organs (by high group IV afferent activity leading to increased Ib inhibitory interneuron activity in the spinal cord) may have the potential to limit neural drive and decrease maximal force output during the high force phase of isometric contractions [52]. However, this reflex arc likely have limited influence on spinal motoneuron

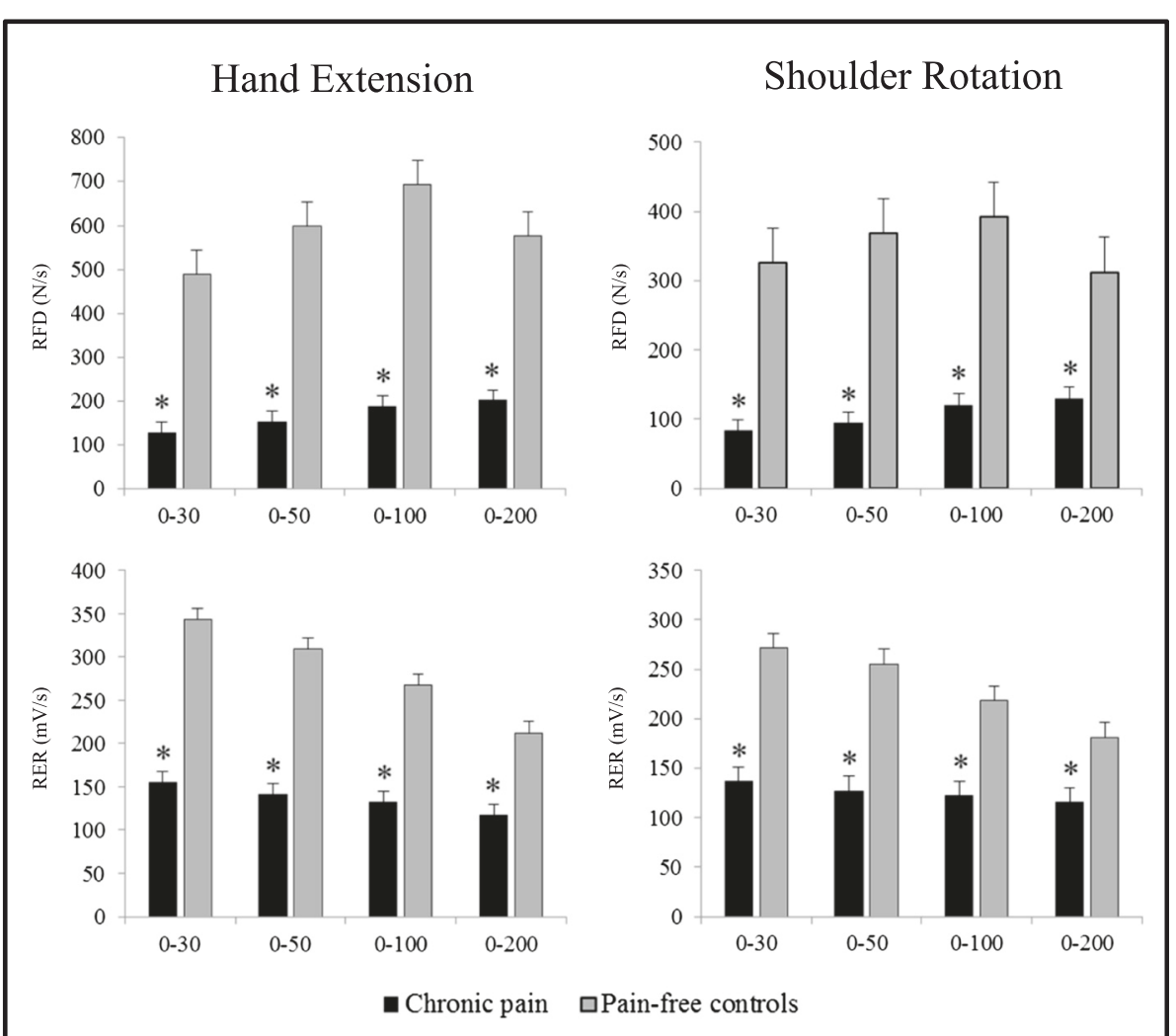

Fig. 3 Rate of force development. Differences in contractile rate of force development (RFD) and rate of EMG rise (RER) for different time-intervals during hand and shoulder MVCs in workers with chronic pain and pain-free controls. A custom made dynamometer was used to measure maximal voluntary contraction strength (MVC) during isometric contractions performed for the shoulder- (external rotation) and wrist muscles (hand extension). Surface EMG was obtained from extensor carpi radialis brevis (during hand extension) and infraspinatus (during shoulder rotation). Mean (SE). * denotes statistical different from pain-free controls 
Table 3 Work-related and clinical differences

\begin{tabular}{|c|c|c|c|c|}
\hline & Chronic pain & Pain-free Control & Between group difference & p-value \\
\hline \multicolumn{5}{|l|}{ Work-related } \\
\hline DASH Work-module (0-100) & 28 (23 to 33$)$ & $0(0$ to 0$)$ & 28 (22 to 34$)$ & $<.0001$ \\
\hline Work Ability Index (7-49) & 39.7 (38.4 to 40.9$)$ & $46.1(45.3$ to 46.9$)$ & $-6.4(-8.1$ to -4.8$)$ & $<.0001$ \\
\hline Item 1: Current work ability compared with the lifetime best (0-10) & $7.3(6.9$ to 7.7$)$ & 9.3 (9.0 to 9.6$)$ & $-2.0(-2.6$ to -1.5$)$ & $<.0001$ \\
\hline Item 2: Work ability in relation to the demands of the job (2-10) & $7.6(7.2$ to 8.0$)$ & 9.0 (8.6 to 9.5$)$ & $-1.4(-2.0$ to -0.9$)$ & $<.0001$ \\
\hline Item 3: Number of current diseases diagnosed by a physician (1-7) & $5.6(5.1$ to 6.0$)$ & $6.4(6.0$ to 6.7$)$ & $-0.8(-1.4$ to -0.2$)$ & 0.0047 \\
\hline Item 4: Estimated work impairment due to diseases (1-6) & 5.7 (5.5 to 5.9$)$ & $6.0(6.0$ to 6.0$)$ & $-0.3(-0.6$ to -0.1$)$ & 0.0003 \\
\hline Item 5: Sick leave during the past year (1-5) & 4.7 (4.5 to 4.9$)$ & $4.9(4.7$ to 5.1$)$ & $-0.2(-0.5$ to 0.2$)$ & 0.2682 \\
\hline Item 6: Own prognosis of work ability two years from now (1-7) & $5.8(5.3$ to 6.3$)$ & $7.0(7.0$ to 7.0$)$ & $-1.2(-1.8$ to -0.6$)$ & $<.0001$ \\
\hline Item 7: Mental resources (1-4) & $3.0(2.8$ to 3.2$)$ & 3.5 (3.3 to 3.7$)$ & $-0.5(-0.8$ to -0.1$)$ & 0.0036 \\
\hline \multicolumn{5}{|l|}{ Clinical } \\
\hline Self-rated health (1-5) & 3.0 (2.8 to 3.2$)$ & $1.7(1.4$ to 2.0$)$ & $1.3(1.0$ to 1.6$)$ & $<.0001$ \\
\hline Fear Avoidance (1-4) & 2.6 (2.4 to 2.8$)$ & $1.1(1.0$ to 1.1$)$ & $1.5(1.2$ to 1.8$)$ & $<.0001$ \\
\hline PPT tibialis Anterior (kPa) & 805 (701 to 910$)$ & 1014 (900 to 1130) & $-210(-342$ to -78$)$ & 0.0020 \\
\hline PPT extensor Carpi Radialis Brevis (kPa) & 639 (554 to 725$)$ & 918 (824 to 1013) & $-279(-387$ to -171$)$ & $<.0001$ \\
\hline PPT infraspinatus (kPa) & 573 (494 to 652) & 753 (666 to 839) & $-180(-280$ to -81$)$ & 0.0004 \\
\hline
\end{tabular}

Work ability index score, work disability (DASH-work module), self-rated health, fear avoidance and pressure pain threshold (PPT) in workers with chronic pain and pain-free controls. Mean $(95 \% \mathrm{Cl})$

activation during the very early phase of rising muscle force, where instead, feed-forward mechanisms, such as fear avoidance, may have the potential to limit motor output and thus neural drive [14]. In the present study we found enhanced fear avoidance (i.e. that fast and forceful arm movement exacerbates pain) in the group of workers with chronic pain compared to pain-free controls. Thus, it seems possible that psychological pain related beliefs could have influenced initial muscle activation and thus rate of force development, in workers with chronic pain.

The results are likely to have a significant functional impact on the repetitive and forceful arm, shoulder and hand motions during slaughterhouse work possibly by weakening joint stability, motor control and precision during cutting and tearing tasks. This is additionally supported by the higher work disability score, as assessed by the work

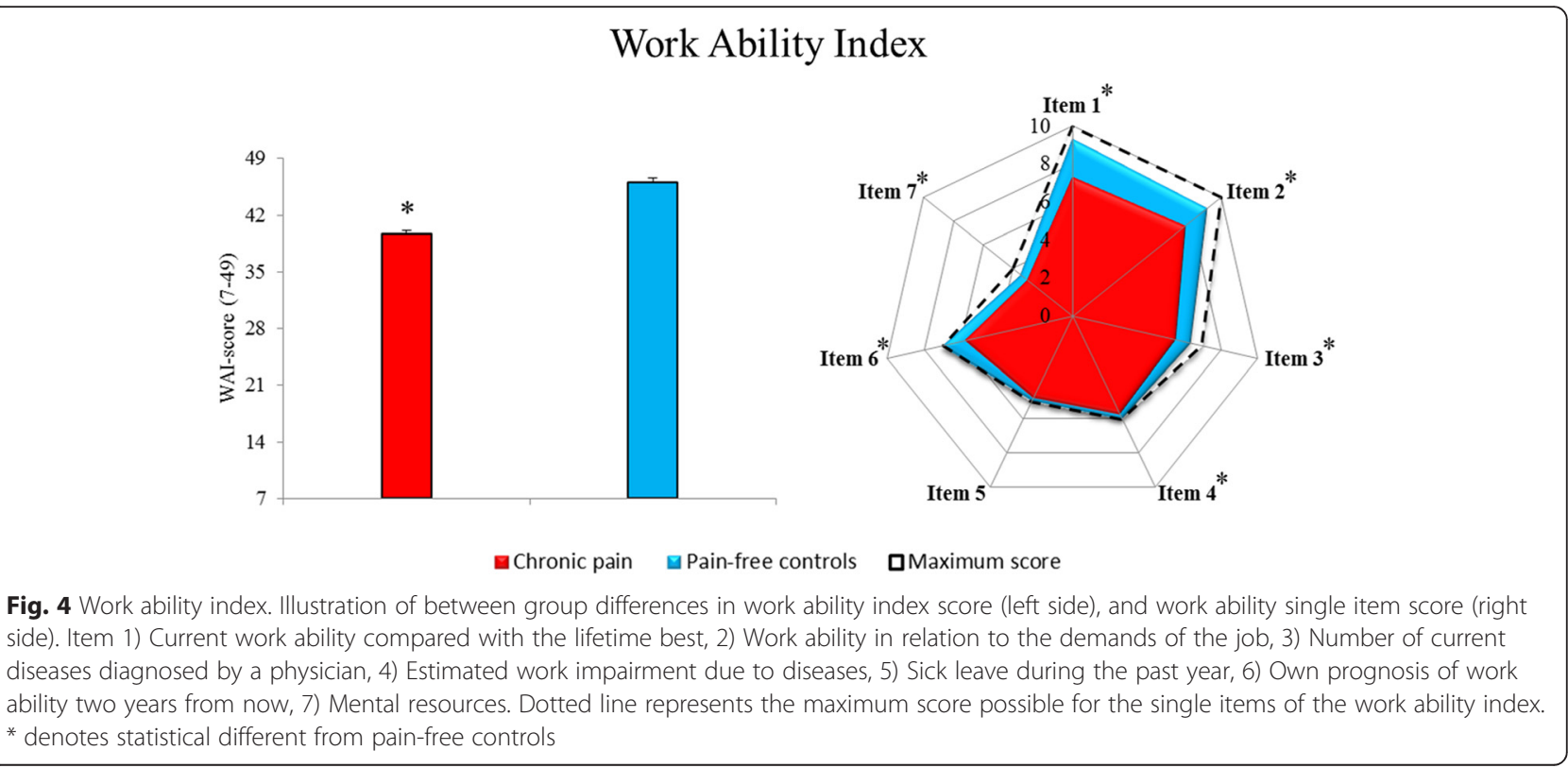


module of the DASH questionnaire, among the workers with chronic pain. Hence, chronic pain was paralleled by functional impairment of the arm, shoulder and hand during daily work tasks indicating an imbalance between individual capacity and work demands. This is further acknowledged, by the observed reduction in work ability (i.e. lowered WAI-score) in the chronic pain group (Fig. 4). The concept of work ability reflects the relation between capacity of the worker and demands of the work, and takes into consideration both demands of the work, health status, and physical and mental resources [53, 54]. As a multidimensional instrument, work ability (index) has been related to musculoskeletal pain, chronic disease, productivity, sickness absence, early retirement and all-cause mortality [29-32, 55]. Likewise, workers exposed to highly repetitive and forceful exertion, lack of sufficient recovery, and awkward postures [24, 25] have an elevated risk of both impaired work ability and musculoskeletal disorders [26-28]. Despite lower work ability in the group with chronic pain observed in the present study, ther index score of 39.7 was still categorized as good. Additionally, when analyzing the items of the WAI separately, no difference in item 5, regarding sick leave during the past year existed between the groups (Fig. 4). Thus, in this group of workers, chronic upper limb pain is paralleled with selfreported decreased work productivity, evidenced by impaired work performance and work ability (DASH-W and WAI) without having direct consequences on sick leave. Consequently, in the present study, chronic pain seems to foster presenteeism (i.e. decreased on the-the-job performance due to health problems) while not leading to absenteeism, which is further acknowledged by the fact that the group with chronic pain were active on the labor market working fulltime at the slaughterhouse [56]. It should however be mentioned, that the differences in DASH and WAI score could potentially be attributed to the inclusion criteria, as participants in the two groups were selected to be different in perceived work disability.

The biopsychosocial model consider chronic pain and disability as the consequences of the dynamic interplay between physiological, psychological, and social factors [6]. In the present study, the chronicity of pain among this group of workers was established by self-reported inclusion criteria and further objectively recognized by an observed parallelism between pain and indicators of neural alterations (central sensitization). Besides obvious biological deficiencies, such as reduced strength and rapid force capacity, also impaired psychosocial features were present in the participants with chronic pain (fear avoidance and WAI item 7 on mental resources). The interaction of the abovementioned factors could have led to an imbalance between individual capacity and work demands, as evidenced by impaired work ability and work disability, consequently affecting overall health (i.e. self-rated health) among the workers with chronic pain. Self-rated health is a major independent predictor of objective health, morbidity and mortality [57-59] and especially symptoms such as chronic pain and fatigue are important constituents of self-rated health. Additionally, chronic pain is independently and significantly related to self-rated health [60] and impaired general health is associated with poor recovery from chronic pain [61]. Future studies on upper limb chronic pain management must carefully consider the biopsychosocial nature of pain in order to augment treatment success.

\section{Strength and limitations}

Our study has both strengths and limitations. Combining direct measures of pressure pain threshold and rapid force capacity with subjective reporting of pain and its biopsychosocial consequences is a strength. A study limitation was that no muscle biopsies were obtained to examine intramuscular differences potentially accountable for the observed reduction of rapid force capacity and maximal muscle strength. Finally, the exclusion and inclusion criteria used in this cross-sectional study confines the generalizability of the results to individuals with chronic upper limb pain exposed to highly repetitive and forceful job tasks.

\section{Conclusions}

Chronically painful upper limb muscles demonstrated impaired rapid force capacity and neural activation compared to non-painful muscles. Further, workers with chronic pain showed impaired work ability, work disability and general health compared to pain-free controls. Future studies on rehabilitation of upper limb chronic pain in workers with physically demanding job tasks must carefully consider the biopsychosocial nature of pain in order to augment treatment success.

\section{Abbreviations}

DASH: Disability of the Arm, Shoulder and Hand questionnaire;

EMG: Electromyography; MVC: Maximal Voluntary Contraction; PPT: Pressure Pain Threshold; RER: Rate of EMG Rise; RFD: Rate of Force Development; VAS: Visual Analog Scale; WAI: Work Ability Index.

\section{Competing interests}

The authors declare that they have no competing interests.

\section{Authors' contributions}

ES, LLA and PA conceived the idea and design of the project and all authors participated in the methodologically development. ES, MDJ, MB and KJ performed the clinical examination. ES, MDJ and LLA carried out the data analysis and LLA performed the statistical analysis. All authors read and approved the final manuscript.

\section{Acknowledgements}

The authors thank Jørgen Skotte and Klaus Hansen from the National Research Centre for the Working Environment for valuable technical assistance and support. This study was supported by a grant from the Danish Parliament 
(Satspuljen 2012; Nye Veje) grant number § 17.21.02.60 and a grant from the Danish Working Environment Research Fund (Grant no. 48- 2010-03).

\begin{abstract}
Author details
${ }^{1}$ National Research Centre for the Working Environment, Lersø Parkalle 105, Copenhagen, Denmark. ${ }^{2}$ Institute for Sports Science and Clinical Biomechanics, SDU Muscle Research Cluster (SMRC), University of Southern Denmark, Odense, Denmark. ${ }^{3}$ Physical Activity and Human Performance Group, Center for Sensory-Motor Interaction, Department of Health Science and Technology, Aalborg University, Aalborg, Denmark. Institute for Sport and Clinical Biomechanics, Department of physical activity and health, University of Southern Denmark, Odense, Denmark.
\end{abstract}

Received: 26 August 2015 Accepted: 17 February 2016

Published online: 27 February 2016

\section{References}

1. Sundstrup E, Jakobsen MD, Jay K, Brandt M, Andersen LL. High intensity physical exercise and pain in the neck and upper limb among slaughterhouse workers: cross-sectional study. BioMed Res Int. 2014;2014:218546.

2. Sundstrup E, Jakobsen MD, Andersen CH, Jay K, Persson R, Aagaard P, Andersen $\mathrm{LL}$. Effect of two contrasting interventions on upper limb chronic pain and disability: a randomized controlled trial. Pain Physician. 2014;17:145-54.

3. Magnusson M, Ortengren R, Andersson GB, Petersén I, Sabel B. An ergonomic study of work methods and physical disorders among professional butchers. Appl Ergon. 1987;18:43-50.

4. Punnett L, Wegman DH. Work-related musculoskeletal disorders: the epidemiologic evidence and the debate. J Electromyogr Kinesiol. 2004;14:13-23.

5. Turk DC, Wilson HD, Cahana A. Treatment of chronic non-cancer pain. Lancet. 2011;377:2226-35.

6. Gatchel RJ, Peng YB, Peters ML, Fuchs PN, Turk DC. The biopsychosocial approach to chronic pain: scientific advances and future directions. Psychol Bull. 2007:133:581-624.

7. Fernández-de-las-Peñas $C$, de la Llave-Rincón Al, Fernández-Carnero J, Cuadrado ML, Arendt-Nielsen L, Pareja JA. Bilateral widespread mechanical pain sensitivity in carpal tunnel syndrome: evidence of central processing in unilateral neuropathy. Brain J Neurol. 2009:132(Pt 6):1472-9.

8. Petzke F, Clauw DJ, Ambrose K, Khine A, Gracely RH. Increased pain sensitivity in fibromyalgia: effects of stimulus type and mode of presentation. Pain. 2003;105:403-13.

9. O'Neill S, Manniche C, Graven-Nielsen T, Arendt-Nielsen L. Generalized deep-tissue hyperalgesia in patients with chronic low-back pain. Eur J Pain Lond Engl. 2007;11:415-20.

10. Andersen $\mathrm{LL}$, Andersen $\mathrm{CH}$, Sundstrup $\mathrm{E}$, Jakobsen MD, Mortensen OS, Zebis MK. Central adaptation of pain perception in response to rehabilitation of musculoskeletal pain: randomized controlled trial. Pain Physician. 2012;15:385-94

11. Bandholm T, Rasmussen L, Aagaard P, Jensen BR, Diederichsen L. Force steadiness, muscle activity, and maximal muscle strength in subjects with subacromial impingement syndrome. Muscle Nerve. 2006:34:631-9.

12. Camargo PR, Avila MA, de Oliveira AB, Asso NA, Benze BG, de Fátima ST. Shoulder abduction torque steadiness is preserved in subacromial impingement syndrome. Eur J Appl Physiol. 2009;106:381-7.

13. Andersen LL, Andersen CH, Skotte JH, Suetta C, Søgaard K, Saltin B, Sjøgaard G. High-intensity strength training improves function of chronically painful muscles: case-control and RCT studies. BioMed Res Int. 2014;2014:187324.

14. Andersen LL, Holtermann A, Jørgensen MB, Sjøgaard G. Rapid muscle activation and force capacity in conditions of chronic musculoskeletal pain. Clin Biomech Bristol Avon. 2008:23:1237-42

15. Van Cutsem M, Duchateau J, Hainaut K. Changes in single motor unit behaviour contribute to the increase in contraction speed after dynamic training in humans. J Physiol. 1998;513(Pt 1):295-305.

16. Aagaard P. Training-induced changes in neural function. Exerc Sci Rev. 2003:31:61-7.

17. Aagaard P, Simonsen EB, Andersen $J$, Magnusson P, Dyhre-Poulsen P. Increased rate of force development and neural drive of human skeletal muscle following resistance training. J Appl Physiol. 2002;93:1318-26.

18. Harridge $\mathrm{S}$. The muscle contractile system and its adaptationto training. In: Human muscular function during dynamicexercise. Basel: Karger; 1996. p. 82-94.

19. Bojsen-Moller J, Magnusson SP, Rasmussen LR, Kjaer M, Aagaard P. Muscle performance during maximal isometric and dynamic contractions is influenced by the stiffness of the tendinous structures 2. J Appl Physiol. 2005:99:986-94.

20. Reneman MF, Schiphorts Preuper HR, Kleen M, Geertzen JHB, Dijkstra PU. Are pain intensity and pain related fear related to functional capacity evaluation performances of patients with chronic low back pain? J Occup Rehabil. 2007:17:247-58.

21. Vlaeyen JW, Linton SJ. Fear-avoidance and its consequences in chronic musculoskeletal pain: a state of the art. Pain. 2000;85:317-32.

22. Gross DP. Are functional capacity evaluations affected by the patient's pain? Curr Pain Headache Rep. 2006;10:107-13.

23. Kamaleri Y, Natvig B, Ihlebaek CM, Benth JS, Bruusgaard D. Number of pain sites is associated with demographic, lifestyle, and health-related factors in the general population. Eur J Pain Lond Engl. 2008;12:742-8.

24. van Rijn RM, Huisstede BM, Koes BW, Burdorf A. Associations between work-related factors and specific disorders of the shoulder-a systematic review of the literature. Scand J Work Environ Health. 2010;36:189-201.

25. Bernard B.P. Musculoskeletal disorders and workplace factors: A critical review of epidemiologic evidence for work-related musculoskeletal disorders of the neck, upper extremity, and low back. Atlanta, Georgia: U.S. Department of Health and Human Services; 1997.

26. van den Berg TIJ, Elders LAM, de Zwart BCH, Burdorf $A$. The effects of workrelated and individual factors on the Work Ability Index: a systematic review. Occup Environ Med. 2009:66:211-20.

27. Alavinia S, van den Berg TIJ, van Duivenbooden C, Elders LAM, Burdorf A. Impac of work-related factors, lifestyle, and work ability on sickness absence among Dutch construction workers. Scand J Work Environ Health. 2009;35:325-33.

28. Andersen $\mathrm{JH}$, Haahr JP, Frost P. Risk factors for more severe regional musculoskeletal symptoms: a two-year prospective study of a general working population. Arthritis Rheum. 2007;56:1355-64.

29. Tuomi K, Ilmarinen J, Eskelinen L, Järvinen E, Toikkanen J, Klockars M. Prevalence and incidence rates of diseases and work ability in different work categories of municipal occupations. Scand J Work Environ Health. 1991;17 Suppl 1:67-74

30. Seitsamo J, Martikainen R. Work ability and all cause mortality: A 25-year longitudinal study among Finnish municipal workers. In: Kumashiro M editor. Promotion of workability towards productive ageing. London: Taylor and Francis Group; 2009. p. 101-4.

31. Neupane S, Miranda H, Virtanen P, Siukola A, Nygård C-H. Multi-site pain and work ability among an industrial population. Occup Med Oxf Engl. 2011;61:563-9.

32. Vänni K, Virtanen P, Luukkaala T, Nygård C-H. Relationship between perceived work ability and productivity loss. Int J Occup Saf Ergon JOSE. 2012;18:299-309.

33. Sundstrup E, Jakobsen MD, Brandt M, Jay K, Persson R, Aagaard P, Andersen LL. Workplace strength training prevents deterioration of work ability among workers with chronic pain and work disability: a randomized controlled trial. Scand J Work Environ Health. 2014:40:244-51.

34. Beaton DE, Katz JN, Fossel AH, Wright JG, Tarasuk V, Bombardier C. Measuring the whole or the parts? Validity, reliability, and responsiveness of the Disabilities of the Arm, Shoulder and Hand outcome measure in different regions of the upper extremity. J Hand Ther Off J Am Soc Hand Ther. 2001;14:128-46.

35. Andersen LL, Andersen JL, Suetta C, Kjaer M, Søgaard K, Sjøgaard G. Effect of contrasting physical exercise interventions on rapid force capacity of chronically painful muscles. J Appl Physiol Bethesda Md 1985. 2009:107:1413-9.

36. Jakobsen MD, Sundstrup E, Persson R, Andersen CH, Andersen LL. Is Borg's perceived exertion scale a useful indicator of muscular and cardiovascular load in blue-collar workers with lifting tasks? A cross-sectional workplace study. Eur J Appl Physiol. 2014;114:425-34.

37. Sundstrup E, Jakobsen MD, Andersen CH, Bandholm T, Thorborg K, Zebis MK, Andersen LL. Evaluation of elastic bands for lower extremity resistance training in adults with and without musculo-skeletal pain. Scand J Med Sci Sports. 2014;24:e353-9.

38. Jakobsen MD, Sundstrup $\mathrm{E}$, Andersen $\mathrm{CH}$, Bandholm T, Thorborg K, Zebis MK, Andersen LL. Muscle activity during knee-extension strengthening exercise performed with elastic tubing and isotonic resistance. Int J Sports Phys Ther. 2012;7:606-16

39. Ilmarinen J. The Work Ability Index (WAI). Occup Med (Lond). 2007:57:2160.

40. Andersen LL, Saervoll CA, Mortensen OS, Poulsen OM, Hannerz H, Zebis MK. Effectiveness of small daily amounts of progressive resistance training for frequent neck/shoulder pain: randomised controlled trial. Pain. 2011;152:440-6. 
41. Pincus T, Bergman M, Sokka T, Roth J, Swearingen C, Yazici Y. Visual analog scales in formats other than a 10 centimeter horizontal line to assess pain and other clinical data. J Rheumatol. 2008;35:1550-8.

42. Kuorinka I, Jonsson B, Kilbom A, Vinterberg H, Biering-Sørensen F, Andersson G, Jørgensen K. Standardised Nordic questionnaires for the analysis of musculoskeletal symptoms. Appl Ergon. 1987;18:233-7.

43. Ware JE, Sherbourne CD. The MOS 36-item short-form health survey (SF-36). I. Conceptual framework and item selection. Med Care. 1992;30:473-83.

44. Sirois FM. Who Looks Forward to Better Health? Personality Factors and Future Self-Rated Health in the Context of Chronic Illness. Int J Behav Med. 2015;22(5):569-79.

45. Persson AL, Brogårdh C, Sjölund BH. Tender or not tender: test-retest repeatability of pressure pain thresholds in the trapezius and deltoid muscles of healthy women. J Rehabil Med. 2004;36:17-27.

46. Ylinen J, Nykänen $\mathrm{M}$, Kautiainen $\mathrm{H}$, Häkkinen A. Evaluation of repeatability of pressure algometry on the neck muscles for clinical use. Man Ther. 2007:12:192-7.

47. Shi Q, Pavey ES, Carter RE. Bonferroni-based correction factor for multiple, correlated endpoints. Pharm Stat. 2012;11:300-9.

48. Kamen G, Knight CA. Training-related adaptations in motor unit discharge rate in young and older adults. J Gerontol A Biol Sci Med Sci. 2004;59:1334-8.

49. Woolf CJ. Central sensitization: implications for the diagnosis and treatment of pain. Pain. 2011;152(3 Suppl):S2-15.

50. Woolf CJ, Salter MW. Neuronal plasticity: increasing the gain in pain Science. 2000;288:1765-9.

51. Bergman S. Management of musculoskeletal pain. Best Pract Res Clin Rheumatol. 2007;21:153-66.

52. Graven-Nielsen $T$, Lund $H$, Arendt-Nielsen $L$, Danneskiold-Samsøe B, Bliddal $H$ Inhibition of maximal voluntary contraction force by experimental muscle pain: a centrally mediated mechanism. Muscle Nerve. 2002;26:708-12.

53. Ilmarinen J, Tuomi K. Past, Present and Future of Work Ability. People Work -Res Rep J Hels Finl Finn Inst Occup Health. 2004;65:581-9.

54. IImarinen J. Work ability-a comprehensive concept for occupational health research and prevention. Scand J Work Environ Health. 2009;35:1-5.

55. Alavinia S, de Boer AGEM, van Duivenbooden JC, Frings-Dresen MHW, Burdorf A. Determinants of work ability and its predictive value for disability. Occup Med Oxf Engl. 2009:59:32-7.

56. Agaliotis M, Mackey MG, Jan S, Fransen M. Burden of reduced work productivity among people with chronic knee pain: a systematic review. Occup Environ Med. 2014;71:651-9.

57. Jylhä M. What is self-rated health and why does it predict mortality? Towards a unified conceptual model. Soc Sci Med 1982. 2009;69:307-16.

58. Idler EL, Benyamini Y. Self-rated health and mortality: a review of twenty-seven community studies. J Health Soc Behav. 1997:38:21-37.

59. Mora PA, Orsak G, DiBonaventura MD, Leventhal EA. Why do comparative assessments predict health? The role of self-assessed health in the formation of comparative health judgments. Health Psychol. 2013;32:1175-8.

60. Mäntyselkä PT, Turunen JHO, Ahonen RS, Kumpusalo EA. Chronic pain and poor self-rated health. JAMA. 2003;290:2435-42.

61. Elliott AM, Smith BH, Hannaford PC, Smith WC, Chambers WA. The course of chronic pain in the community: results of a 4-year follow-up study. Pain. 2002;99:299-307.

\section{Submit your next manuscript to BioMed Central and we will help you at every step:}

- We accept pre-submission inquiries

- Our selector tool helps you to find the most relevant journal

- We provide round the clock customer support

- Convenient online submission

- Thorough peer review

- Inclusion in PubMed and all major indexing services

- Maximum visibility for your research

Submit your manuscript at www.biomedcentral.com/submit

) Biomed Central 